\title{
OPEN An ecological analysis of snakes captured by C.J.P. Ionides in eastern Africa in the mid-1900s
}

\author{
Richard Shine ${ }^{1 *}{ }^{1 *}$ \& Stephen Spawls ${ }^{1,2}$ \\ Historical data can clarify ecological attributes of fauna in sites that have subsequently been altered \\ by anthropogenic activities. We used the 1960 s notebooks of pioneering East African naturalist C.J.P. \\ lonides to extract quantitative information on captures of 484 snakes of five species (rhinoceros vipers \\ Bitis nasicornis, black mambas Dendroaspis polylepis, Jameson's mambas D. jamesoni, water cobras \\ Naja annulata, and eastern forest cobras N. subfulva). High capture rates suggest high abundances \\ of all species. The relative numbers of each species collected changed over the years and differed \\ seasonally, reflecting targeting by lonides. Sex ratios and age-class distributions differed among species \\ and were affected by factors such as month of collection and time of day. Habitat use was affected \\ by species, sex and body size: for example, arboreality became less common with increasing body \\ size in the rhinoceros viper and black mamba, and males were found in arboreal sites more often than \\ were females. In both $D$. jamesoni and $D$. polylepis, adult males and females were recorded together in \\ September-October, suggesting reproductive activity at this time of year. Although fragmentary, the \\ data from lonides' notebooks provide a unique glimpse into ecological patterns of snakes within an \\ African landscape half a century ago.
}

For snakes, as for many kinds of organisms, our knowledge of ecological traits is based primarily on studies of a small subset of species from a limited set of locations. In particular, taxa from areas within the tropics have been understudied relative to those from temperate-zone habitats ${ }^{1}$. Although ecological research on African snakes is beginning to fill that knowledge gap ${ }^{2-8}$, many species, from temperate-zone as well as tropical areas, remain virtually unstudied in the wild. Those taxa include some of the world's largest and most spectacular snakes, such as mambas, cobras and vipers. Research has been discouraged by logistical problems associated with travel and security, as well as by the difficulties inherent in studying large venomous snakes.

The challenge of understanding ecological characteristics of tropical snakes is exacerbated by rapid degradation of habitats by the growing human population, with consequent shifts, and often, declines, in abundance of predators such as snakes ${ }^{9}$. Although that problem is worldwide, it is especially acute in some regions of the tropics, where land-clearing for agriculture has transformed the landscape $\mathrm{e}^{10-12}$ and affected aspects such as soil quality and rates of erosion ${ }^{12-15}$. Such changes may advantage some species of snakes, but disadvantage others ${ }^{4,16-18}$. To understand the situation prior to this kind of habitat change, we must rely on historical records. Ideally, researchers can quantify temporal shifts in organismal abundances and distributions by careful replication of earlier surveys $^{19}$. Even when replication is impractical, however, an analysis of historical data may clarify important aspects of ecosystems in earlier times.

In the present study, we report information on abundances, demography (age-class distributions, sex ratios) and habitat use in five species of large venomous snakes that were collected primarily in the 1950s and 1960s by one of the pioneers of African herpetology. Constantine John Philip Ionides (henceforth, "Ionides", 1901 to 1968; see Fig. 1a) was a prominent figure in early scientific collections of herpetofauna in eastern Africa, and his colourful life has been the subject of two biographies ${ }^{20,21}$ and an autobiography ${ }^{22}$. During the latter part of his life, his focus shifted from big-game hunting to snake-collecting ${ }^{23}$. Although Ionides published few scientific papers $^{24}$, he kept a detailed record of all of the large venomous snakes that he captured ${ }^{25}$. Those data are contained within a series of notebooks, some of which were available to us through the generosity of Jonathan Leakey. The pages relating to some of the species that Ionides collected have been removed from the notebooks, and cannot be located; they were presumably sent to C.R.S. Pitman to enable preparation of co-authored papers ${ }^{26,27}$. The 


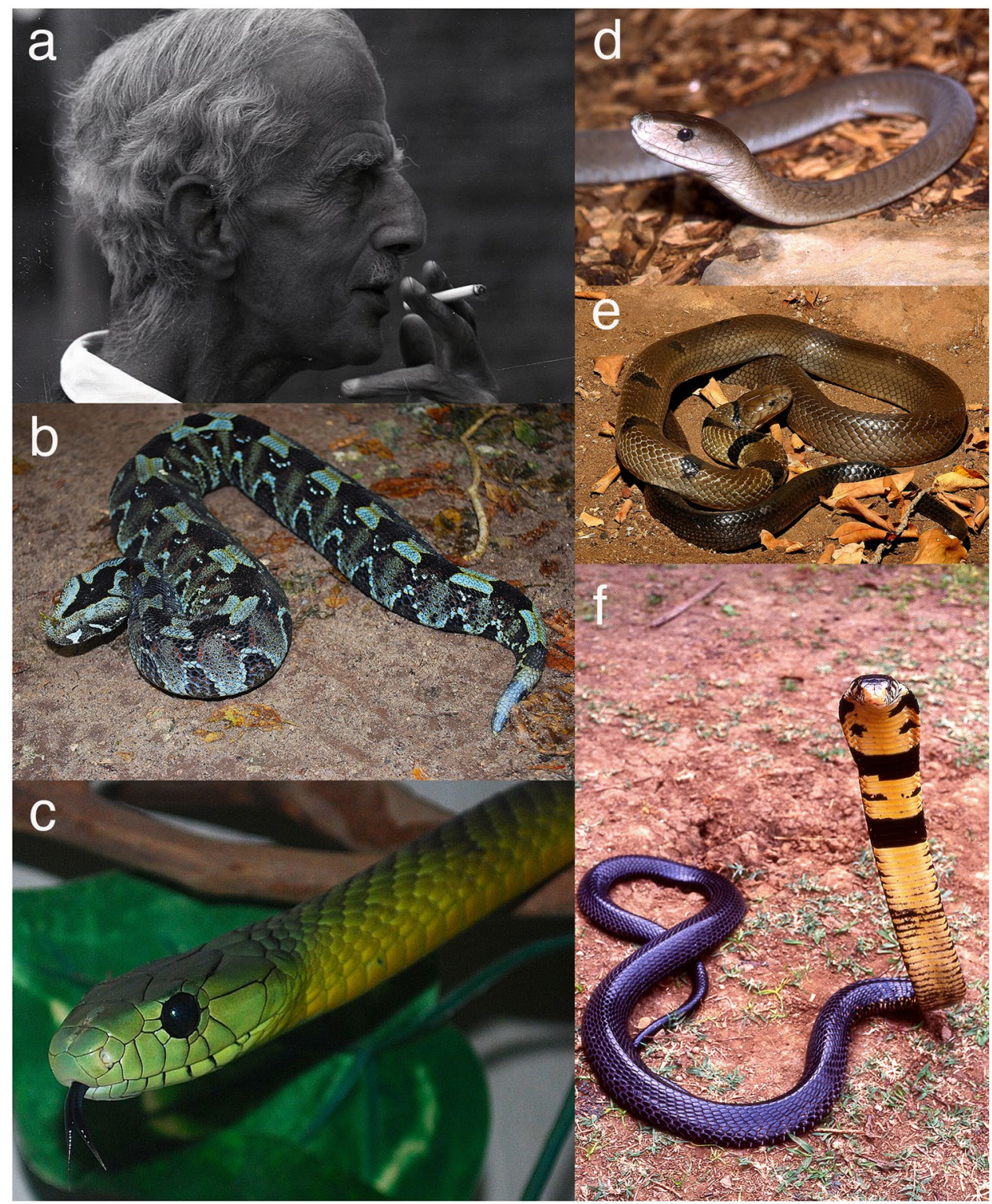

Figure 1. (a) C.J.P. Ionides, and the species of snakes for which data were available from his collection records: (b) rhinoceros viper, Bitis nasicornis; (c) Jameson's mamba, Dendroaspis jamesoni; (d) black mamba, Dendroaspis polylepis; (e) water cobra, Naja annulata; (f) forest cobra, Naja subfulva. Photographs by S. Spawls $(\mathbf{a}, \mathbf{b}, \mathbf{c}, \mathbf{d}$ and $\mathbf{f})$, and W. Wuster (e), with permission.

remaining pages contain data on captures of six other east-African snake species. We have extracted information on five of those species (omitting Elapsoidea sundevallii, represented by only six records) from those notebooks.

The snakes for which we have collection data (location, date, time of day, size class, sex, habitat) represent only a small fraction of Ionides' collections. A page in one of his notebooks includes a running lifetime tally of each species, totalling 10,964 venomous snakes overall. Of these, 6,633 were Dendroaspis angusticeps, 2,159 were Bitis gabonica, 386 were Naja n. nigricollis, 354 were B. arietans, 314 were Causus defilippii, 312 were Echis pyramidum, and 122 were Vipera hindii (= Montatheris hindii). Thus, the five species for which we have examined capture records, which are not included in the above list of "most commonly collected" taxa, constitute less than $5 \%$ of Ionides' total collections (i.e., 484 of 10,964).

\section{Materials and Methods}

Collecting localities. The two species of snakes that Ionides collected in the largest numbers (D. angusticeps and B. gabonica) came from the Makonde Plateau, in the Newala District of Tanzania, within a 20-km radius of his home ${ }^{26}$. In contrast, the species for which we provide data in the current analysis primarily were taken elsewhere, during targeted trips, each of a few weeks in duration, to other localities in east Africa. His Bitis nasicornis were collected from the Ituri Forest, Democratic Republic of the Congo (10 animals) and the Kakamega Forest in Kenya (67 animals). The Kakamega Forest was the only site in which he collected D. jamesoni. In contrast, he 
caught $D$. polylepis from a variety of sites in Kenya, although the species was not found on the Makonde Plateau. Naja subfulva was captured from the Kakamega Forest in Kenya $(N=6)$, the Kisumu region of Kenya $(N=8)$, the Ituri Forest in the Belgian Congo $(N=4)$, Mpungulu in Northern Rhodesia $(N=1)$, and close to Ionides' home in Newala, Tanzania $(N=9)$. Other Tanzanian specimens came from Liwale $(N=3)$ and Tukuya $(N=5)$. Lastly, Naja annulata was collected during trips to the southern end of Lake Tanganyika, in Tanzania $(N=8)$ and Zambia $(N=67)$.

Species. All five species are large and highly venomous snakes; Ionides targeted them because he was able to sell live specimens to zoos, and to scientific institutions for their venom ${ }^{26}$. One species (Bitis nasicornis) is a heavy-bodied viperid, an ambush predator that inhabits forest and does not enter savanna; unlike all other members of the genus, it is partly arboreal. The other four are more slender-bodied elapids (see Fig. 1). Dendroaspis polylepis is the largest African elapid, reaching at least $3.2 \mathrm{~m}$; it is a fast-moving diurnal snake, widespread in the savannas of Africa, confident in defence, with a bad but largely unjustified reputation. Dendroaspis jamesoni is also large, up to $2.64 \mathrm{~m}$, but is a more secretive diurnal inhabitant of the forests of central Africa, from western Kenya west to Nigeria. Naja annulata is a poorly known elapid that seems to spend much of its time in water, both lakes and rivers, hunting fish by day. Those collected by Ionides were of an eastern subspecies, Naja annulata stormsi, largely confined to Lake Tanganyika, although the nominate subspecies extends west right through the forest to Cameroon. Naja subfulva, recently redefined, is a large alert diurnal cobra, reaching $2.7 \mathrm{~m}$, and variable in colour. It has a large but patchy distribution in forest, woodland and wooded savanna, from eastern South Africa north to Ethiopia, and west to northern Cameroon. Two of the species collected by Ionides have been subject to recent changes in nomenclature. The water cobra was long known as Boulengerina annulata, but it has since been transferred to the genus $\mathrm{Naja}^{28}$. The widely-distributed forest cobra "Naja melanoleuca" has recently been shown to consist of five lineages; the one captured by Ionides is $N$. subfulva $a^{29}$.

Methods. Ionides' collection dates span the period from 1945 to 1968 , with most $(446$ of $484,=92 \%)$ falling between 1958 and 1966. One-quarter of all records (125) came from 1965. Ionides undertook trips to collect particular species only when he had a specific order from his clients ${ }^{26}$, but the seasonal timing of trips also depended on logistical issues. He travelled away from his home between July and October because those are the low rainfall months in southeast Tanzania; and that timing allowed him to collect snakes on the Makonde Plateau for scientific institutions during the rainy season (November through to April or May in southern Tanzania). As a result, the seasonal timing of Ionides' captures says little about seasonal activity of the snakes. We nonetheless report these and related variables, because of their historical interest and to enable future comparisons with other datasets.

Ionides offered financial rewards to people from local villages to find snakes and alert him to their presence ${ }^{26}$. He then travelled to the site to collect the animal ${ }^{25}$. The time at which a snake was caught thus may say little about when the animal was active; hours may have elapsed between the time the animal was sighted and the time that Ionides captured it, especially since he was unable to walk long distances, and instead had to be transported in a specially-constructed wheelchair ${ }^{25}$. Another important bias in the notebook records was that Ionides collected mainly large snakes, and he did not record all of the juveniles that were reported to him $^{26}$. Hence, his data overestimate the proportion of adult animals among the total sample that he had the opportunity to collect. The magnitude of this bias differed among species, however: he notes that few juvenile mambas were seen, whereas his samples of viperids contained animals of a wide range of body sizes ${ }^{26}$.

Whenever Ionides captured a snake he recorded its locality (general region only), date and time of capture, sex and life $\operatorname{stage}^{26}$ (Fig. 2). His life-stage classification was as follows: "adult", estimated hatched or born more than two years previously; "fair-size", born or hatched two years previously; "half-grown", born or hatched the previous year; and "juvenile", born or hatched the same year. He also provided brief notes as to the habitat in which the snake was captured - for example, if it was in water or up a tree (and for B. nasicornis only, he recorded heights above ground), and he noted if two snakes were found in the same location at the same time.

Statistical methods. We entered all of the data from Ionides' notebooks into a spreadsheet, and we used JMP 13.0 (SAS Institute, Cary, NC) to conduct statistical analyses. All variables conformed to normality of distributions and variance homogeneity, so no transformations were needed prior to analysis. For continuous dependent variables, we used ANOVA to investigate significant associations among variables. For nominal and ordinal dependent variables, we used logistic regression to explore the statistical significance of departures from relevant null hypotheses. We treated "life stage" as an ordinal variable. In analyses with multiple independent variables, we included all interaction terms between factors, but deleted non-significant interactions $(p>0.05)$ and recalculated main effects. We did not correct for artifactually significant results due to multiple testing, because of the subjectivity inherent in defining groups of related tests ${ }^{30}$.

\section{Results}

After excluding data for Elapsoidea because of the small sample size, we were left with data for 77 Bitis nasicornis, 68 Dendroaspis jamesoni, 228 D. polylepis, 36 Naja subfulva and 75 N. annulata.

Rates of capture. The most striking feature of Ionides' records is the high daily rates of capture. For example, he collected 47 D. polylepis within a two-week period (in October 1965), 34 D. jamesoni over a six-week period (September-October 1961), 25 N. annulata over a two-week period (August 1958), and 23 B. nasicornis within a month (October 1961).

Changes in species captured over the years. The relative numbers of each species collected varied strongly through time (nominal logistic regression with year as factor and species as dependent variable; 


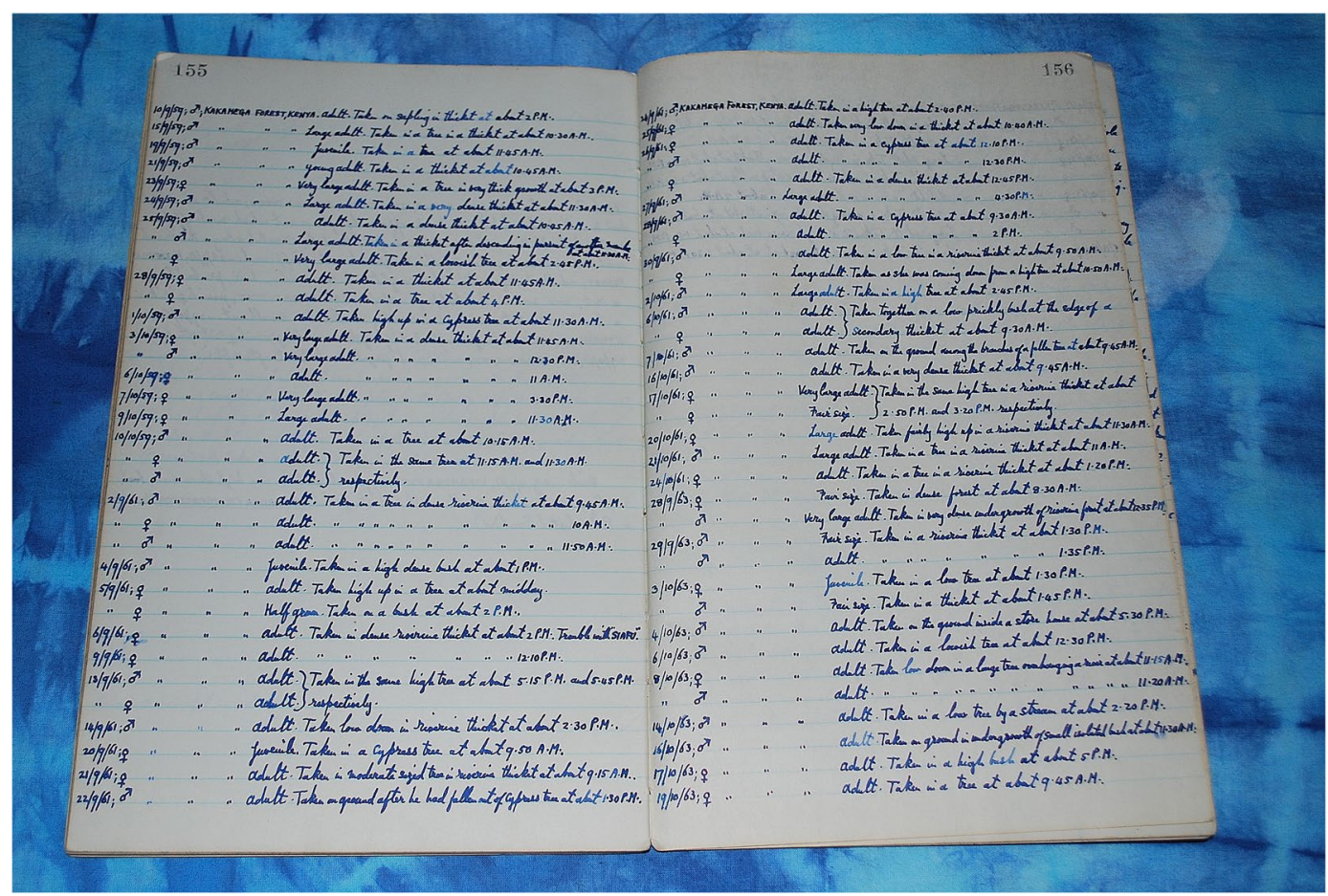

Figure 2. A page from one of Ionides' notebooks, showing the nature of data that he recorded at capture events for one of the targeted species (Dendroaspis jamesoni).

$\chi^{2}=921.56, d f=76, p<0.0001$ ). All of the early records (from 1945 to 1953 ) concern a single taxon (D. polylepis). In contrast, N. annulata and D. jamesoni each were taken in only three years (respectively, 1956, 1958, 1960; and 1959,1961 , and 1963). Bitis nasicornis was collected in 1954,1959, 1961 and 1963. Naja subfulva was taken at lower rates over a longer period (1954 to $1967 ; N=0$ to 9 snakes per year).

Capture month. The monthly distribution of captures differed among species $\left(\chi^{2}=304.22, d f=33\right.$, $p<0.0001$ ), but the primary capture period was August to October for all taxa (Fig. 3). All records of B. nasicornis and D. jamesoni fall within these three months, as do $81 \%$ of captures of D. polylepis and $67 \%$ of N. subfulva. In contrast, N. annulata were taken primarily in July (48\%) and August (44\%).

Capture month vs. life stage. In a two-factor ANOVA with species and life stage as factors, the interaction between these two variables significantly affected month of collection $\left(F_{15,451}=1.82, p<0.03\right)$. However, no relationship between life stage and month of capture was statistically significant when analyses were conducted separately for each species.

Capture month vs. sex. Sex ratios of captured snakes did not differ significantly among months in the overall sample, but monthly variation was significant within $N$. subfulva $\left(F_{10,35}=19.50, p<0.035\right)$. However, the divergence between sexes was minor (female-bias in September, male-bias in October) and unlikely to be biologically significant.

Capture time of day. Except for 10 snakes that Ionides recorded as being captured in the evening (without specific times), all snakes were taken between $0730 \mathrm{~h}$ and $1900 \mathrm{~h}$. There were no strong peaks or troughs within that period, but capture times differed among species. The relative numbers of captures in the morning (versus the afternoon) was $56 \%$ for D. jamesoni, $46.5 \%$ for D. polylepis, $34.2 \%$ for B. nasicornis, $30.6 \%$ for N. subfulva, and $20 \%$ for $N$. annulata. Those interspecific divergences are statistically significant $\left(\chi^{2}=27.03, d f=4, p<0.0001\right)$.

Capture time of day vs. life stage. In a nominal logistic regression, capture time (AM vs. PM) was affected both by species $\left(\chi^{2}=29.79, d f=4, p<0.0001\right)$ and by life stage $\left(\chi^{2}=7.11, d f=1, p<0.008\right.$; interaction term NS so deleted). Figure 4 depicts the effect of life stage on time of capture, with a higher proportion of juveniles captured in the morning and older age classes captured in the afternoon.

Species differences in relative numbers of each life stage. Ionides' samples of all species were dominated by adults (from $61 \%$ in B. nasicornis to $87 \%$ in D. jamesoni), but the proportion of juvenile animals was highest in N. subfulva (19\%) and lowest in D. polylepis (4\%; treating life stage as an ordinal variable, species effect $\left.F_{4,477}=3.62, p<0.007\right)$. 

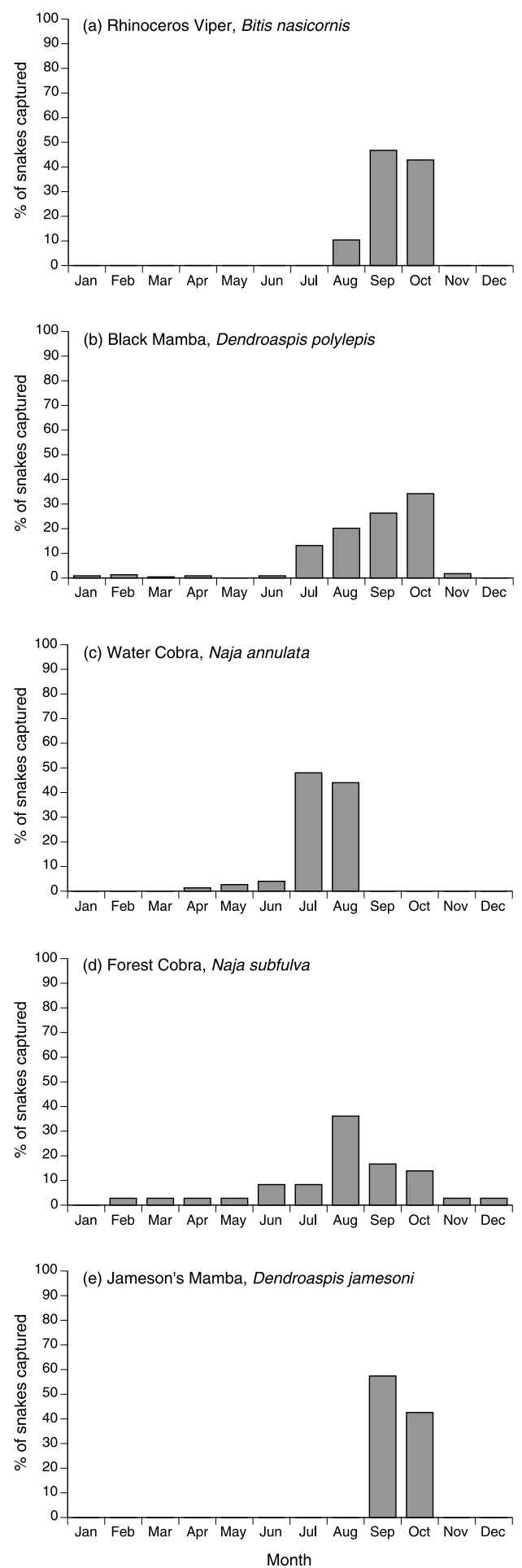

Figure 3. Monthly distribution of capture records for five species of snakes in east Africa, from the notebooks of C.J.P. Ionides.

Sex ratio. Sex ratios of the collected snakes varied among species (logistic regression $-\chi^{2}=16.12, d f=4$, $p<0.003$ ), being female-biased in B. nasicornis (59.7\%) and N. annulata (62.7\%) but male-biased in the terrestrial elapids (D. polylepis $40.8 \%$ female, D. jamesoni $47.1 \%$, N. subfulva $41.7 \%$ ).

If we include life stage as well as species as factors in a nominal logistic regression, sex ratios are influenced by both of these variables (species effect $\chi^{2}=16.09, d f=4, p<0.003$; life stage effect $\chi^{2}=6.60, d f=2, p<0.015$; interaction NS so deleted; see Fig. 5). Samples of younger snakes were female-biased (62.5\% females in juveniles, $67.6 \%$ in half-grown animals) whereas most larger snakes were males ( $45.0 \%$ female in fair-sized animals, $45.4 \%$ in adults). The trend was also statistically significant within $N$. subfulva $\left(\chi^{2}=6.48, d f=3, p<0.011\right)$. 


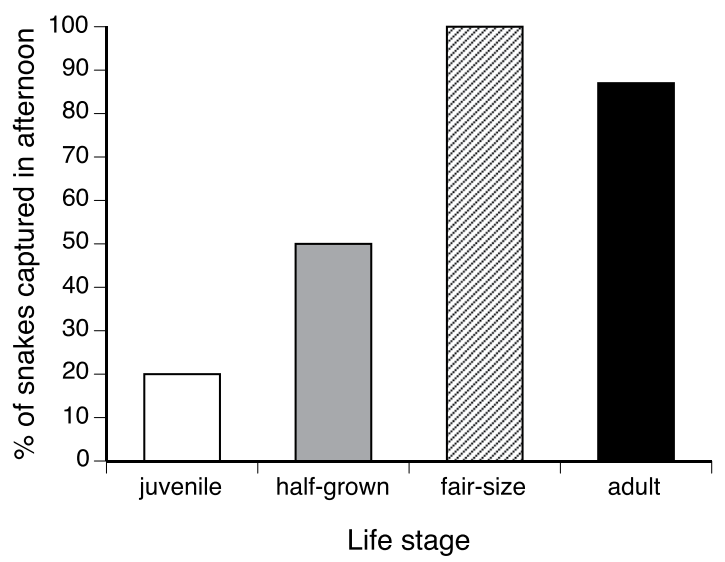

Figure 4. Times of day at which C.J.P. Ionides captured different age classes of snakes of five species. Data are combined for five species, because statistical analysis revealed no significant interspecific differences in these patterns (see text). The histograms show the proportion of total captures for each age class that were caught in the afternoon rather than the morning. Most captures of juvenile snakes were in the morning, whereas larger snakes were generally captured in the afternoon.

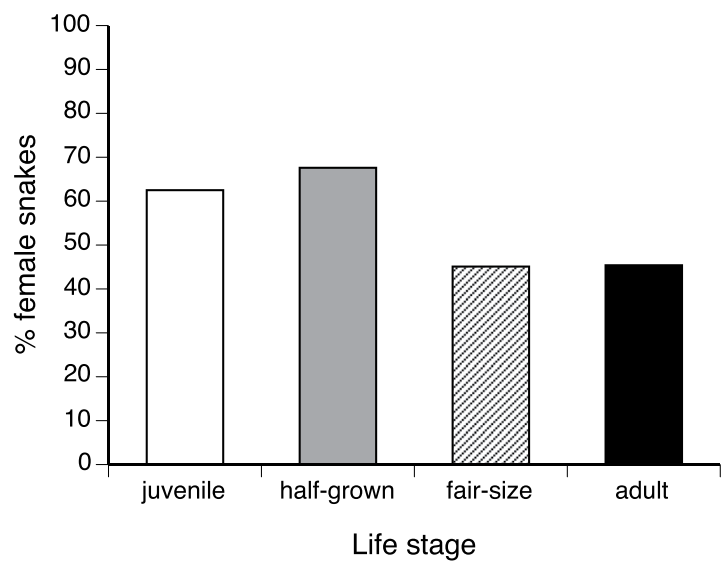

Figure 5. Ontogenetic (age-class) variation in sex ratios of snakes captured by C.J.P. Ionides. Data are combined for five species, because statistical analysis revealed no significant interspecific differences in these patterns (see text). The proportion of snakes that were females declined among larger size classes.

Habitat use. For analysis, we divided habitats into four categories (arboreal, terrestrial, below-ground, in water). The species differed in terms of relative numbers within each of these categories $\left(\chi^{2}=450.70, d f=12\right.$, $p<0.0001$; interaction between species and life stage $\chi^{2}=20.87, d f=12, p=0.052$ ). The species effect reflects a pattern in which the two mamba species were found primarily in trees, the water cobra was found in the water, the rhinoceros viper was found both on the ground and in trees, and the eastern forest cobra was found in all habitats. Looking separately within each species, the ontogenetic shift in habitat use was statistically significant within $B$. nasicornis (shift from arboreal to terrestrial sites with increasing age; $\chi^{2}=8.73, d f=2, p<0.015$ ) and $D$. polylepis (adult snakes more often found in fossorial rather than arboreal sites; $\chi^{2}=7.13, d f=2, p<0.03$; see Fig. 6).

A snake's sex also affected its habitat choice (nominal logistic regression; species effect $\chi^{2}=439.19, d f=12$, $p<0.0001$; sex effect $\chi^{2}=8.88, d f=3, p<0.035$; interaction species*sex NS). The sex difference involved males being found in trees more often than were females (65.4 vs. $51.5 \%)$ and also, being found less often on the ground (21.9 vs. $12.5 \%)$.

For one species (B. nasicornis), Ionides also recorded height above the ground. No significant differences in mean height above ground were evident as a function of a snake's sex $\left(F_{1,21}=0.79, p=0.38\right)$ or its life stage $\left(F_{1,21}=2.64, p=0.12\right.$; and interaction sex $*$ life stage $\left.=\mathrm{NS}\right)$.

Co-occurrence of snakes. Records of snakes found together in the same site may reflect social interactions such as courtship, mating and male-male combat. For D. polylepis, Ionides recorded cases involving two adult males collected from the same antbear hole (October 1965), close to each other within a thicket (October 1959), and smoked out of the same tree (7 days apart, September 1967). A female was captured six days after a male was caught in the same tree (September 1965), a juvenile female and an adult male were both taken from under bark of the same dead tree (October 1965), and an adult male and female were taken from the same antbear hole (October 1965). For Dendroaspis jamesoni, Ionides recorded an adult male plus an adult female in the same trees 

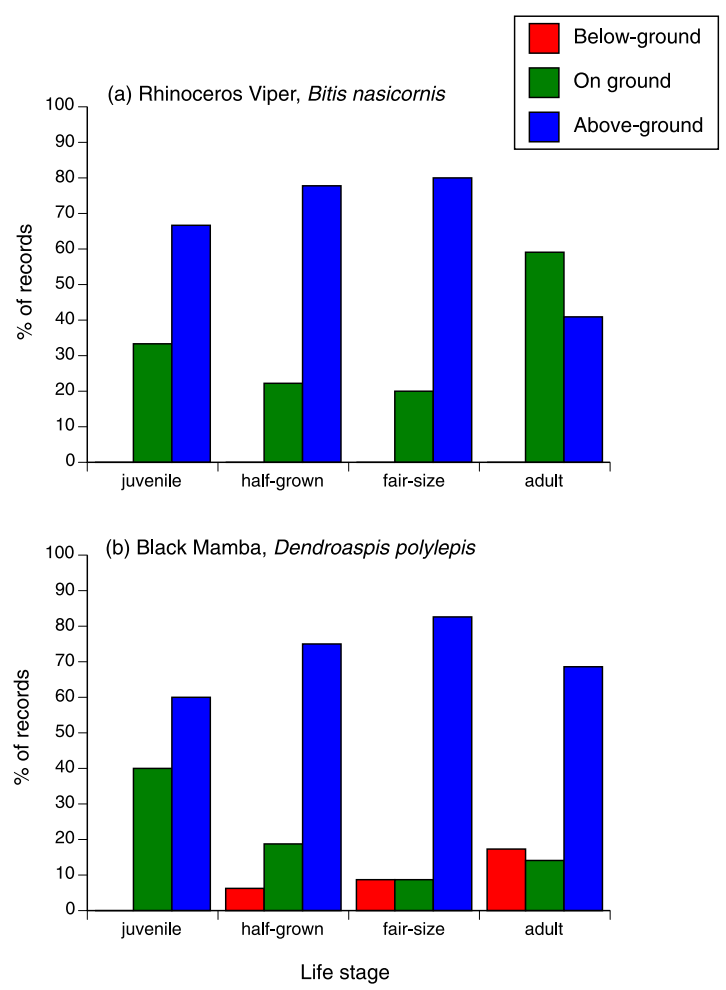

Figure 6. Ontogenetic (age-class) variation in habitat use of rhinoceros vipers Bitis nasicornis, and black mambas Dendroaspis polylepis, captured by C.J.P. Ionides. Arboreality was less common in larger rhinoceros vipers, and fossoriality was more common in larger black mambas.

on four occasions (October 1959, September 1961, October 1961, October 1963), and one additional case of two females (one adult, one fair-sized) in the same tree (October 1963). Lastly, two adult male Naja subfulva were dug out of the same termite mound two days apart in October 1963.

\section{Discussion}

Ionides' methods were designed to maximise the number of specimens that he could capture, not to provide unbiased samples of the abundance and distribution of snakes in his collection sites. He relied upon incidental sightings by others, captured animals only by day, and only targeted particular species when he had orders to fill, and at places where he could be assured of high rates of encounter. Thus, Ionides' notebooks provide only snapshots of the ecology of snakes in east Africa in the 1950s and 1960s, but the data nonetheless can be used to clarify two main issues: the abundance of snakes, and non-random patterns in habitat use with respect to snake species, sex and life stage.

It is clear both from the present dataset, and from published summaries of Ionides' collections of other snake species, that he was able to find and catch large venomous snakes at a rate that seems remarkable in light of other data. For example, Penner et al. ${ }^{31}$ noted that most field studies of Bitis gabonica have been based on total sample sizes of two to nine specimens, although those numbers increased markedly when snakes were also obtained from bushmeat markets or over long periods. In their own field study, Penner et al. ${ }^{31}$ found rhinoceros vipers (B. rhinoceros) by following troops of monkeys through the forest and listening for alarm calls. The researchers averaged 0.01 snake per hour and located a total of 41 individuals within a 770 -ha study area ( 1 snake per 18.8 ha). During concurrent surveys for leaf-litter anurans, investigators found an average of 0.002 vipers per hour ${ }^{31}$. Luiselli ${ }^{32}$ esti- $^{-}$ mated a mean population density of 0.10 individuals per hectare (range 0.01 to 0.30 ) for B. nasicornis, and Bombi et al. ${ }^{33}$ defined "high abundance" sites for B. nasicornis as those in which they found at least two individuals for every 10 hours in the field. For Dendroaspis jamesoni, intensive research resulted in capture of seven adult snakes over a 109-day period, and estimated a density of 0.11 adults per hectare ${ }^{4}$. Population densities at Ionides' main collecting sites appear to have been higher. For example, he captured 973 green mambas (D. angusticeps) between March 1954 and January 1961 within a radius of about 10 miles of his home in Newala ${ }^{26}$. The same paper reports catching 302 gaboon vipers (B. gabonica) in an area of $3 \times 2$ miles, and catching 217 specimens in 47 days (May to June 1961). Perhaps Ionides' most remarkable record is of capturing 18 green mambas (D. angusticeps) and one boomslang (Dispholidus typus) in a three-and-a-half-hour period, and stopping only because his hand became tired $^{34}$. The analyses in the present paper are based on smaller numbers, but the daily rates of capture nonetheless were high. Lacking data on current population densities of snakes in these collecting sites, or any way to translate capture rates to underlying population densities, all we can conclude is that large venomous snakes were abundant half a century ago. That may no longer be the case, at least for some taxa. For example, counts of B. nasicornis at 
a Nigerian study site fell by $>90 \%$ over the period from 1995 to 2008 , whereas counts of $D$. jamesoni remained stable over the same timeframe9.

The size-class distributions of Ionides' snakes differ among species, likely reflecting biological factors (notably, differences in the ease of observing small specimens in different habitats) as well as his focus on larger specimens because of their commercial value. With respect to the two species that he captured in huge numbers near Newala, he notes that the greater abundance of juveniles in gaboon vipers versus green mambas was due to differences in encounter rates rather than due to his own size-selection. The data we analysed show similar patterns; that is, more juveniles in vipers than in mambas. Similar consistency between Ionides' published comments on other species and our own analyses is evident in sex ratios - we found a female bias in rhinoceros vipers as in gaboon vipers, but a male bias in black mambas and Jameson's mambas as in green mambas ${ }^{26}$. Studies on other elapid species have reported that females are encountered more frequently than males in viviparous species where females facilitate embryonic development by basking for long periods in exposed situations, whereas males are encountered more frequently in species in which males travel about extensively during mate-searching activities ${ }^{35}$. Such consistencies suggest that non-random sex ratios in Ionides' collections reflect aspects of snake ecology rather than sampling errors. In subsequent work, Luiselli et al. ${ }^{4}$ and Luiselli and Akani ${ }^{36}$ have reported relatively equal numbers of males and females in field-collected samples of both B. nasicornis and D. jamesoni, but the two species differ in sexual size dimorphism: males grow larger in the mambas whereas females grow larger in the vipers. Importantly, observability of snakes is affected by feeding, as recently-fed animals selected more exposed sites, so were more obvious, and feeding frequencies differ between the sexes (e.g., gravid female B. nasicornis cease feeding $^{32}$ ). These kinds of behavioural differences between the sexes plausibly explain non-random patterns in the sex ratios of animals collected by Ionides.

Ionides' notebooks also provide rich detail about the circumstances of capture of 484 snakes. Strong biases in the timing of his collecting activities mean that we can say little about seasonality of activity or reproduction, but such biases should not affect data on issues such as non-random habitat use with respect to snake species, sex and body size. Broadly, the patterns that we detected are consistent with published results on other species of snakes in other parts of the world. For example, a relative scarcity of juvenile specimens in the relatively arboreal mambas may well reflect observability in this complex habitat, as noted by Ionides and Pitman ${ }^{26}$ for the green mamba $D$. angusticeps. These authors noted that mambas frequently bask in lower and more open areas of the trees in the morning, retreating to thicker foliage later in the day. Presumably smaller snakes would heat up more rapidly ${ }^{37}$, and hence retreat from open sites sooner; and would be more difficult to see within a dense tangle of vegetation. In contrast, juvenile rhinoceros vipers (B. nasicornis) are likely to remain sedentary, and observability of a snake in the ground, especially if encountered during agricultural activities, when the ground is being tilled, may be less dependent on the animal's body size than would be the case for a snake in a tree.

Likewise, a reptile's sex and body size often may affect its use of arboreal habitats ${ }^{38,39}$. The biomechanics of climbing favour elongate morphology and limit the maximum body size that can be supported by a slender branch ${ }^{40}$. Those functional constraints generate simple predictions: that arboreality should be more common (a) in more elongate species, (b) in smaller snakes within a species, and (c) in males not reproductive females, because gravid females are heavily distended with the clutch or litter, especially in viviparous species ${ }^{41}$. In keeping with those predictions, our analysis of Ionides' data recorded arboreality more frequently (a) in slender-bodied species; (b) in smaller age classes within a species, and (c) in males rather than females. We note, however, that other factors might also drive non-random associations between a snake's phenotype and its habitat use. For example, larger snakes may be less arboreal because they are less vulnerable to terrestrial predators, or because they have different thermoregulatory priorities, or because they target different prey types ${ }^{2,4,38,42,43}$.

In summary, some of the associations between ecological variables (time of day, habitat) and snake species, size, and sex likely reflect functional links that are mediated through interspecific and intraspecific variation in behavioural traits. Other non-random patterns within the dataset reflect the behaviour of Ionides (e.g., where and when he collected snakes) rather than of the snakes themselves. Teasing apart the proximate mechanisms involved, and documenting wider aspects of the ecology of these iconic snakes, remains a challenge for future researchers who follow in the footsteps (or rather, wheelchair tracks) of this intrepid pioneering snake biologist.

\section{Data availability}

The datasets generated and analysed in this study are available from the corresponding authors on reasonable request.

Received: 27 October 2019; Accepted: 6 January 2020;

Published online: 20 March 2020

\section{References}

1. Mullin, S. J. \& Seigel, R. A. Snakes: Ecology and Conservation. (Cornell University Press, 2009).

2. Branch, W. R., Haagner, G. V. \& Shine, R. Is there an ontogenetic shift in mamba diet? Taxonomic confusion and dietary records for black and green mambas (Dendroaspis: Elapidae). Herpetol. Nat. Hist. 3, 171-178 (1995).

3. Spawls, S. \& Branch, B. The Dangerous Snakes of Africa. Natural History. Species Directory. Venoms and Snakebite. (Blandford, 1995).

4. Luiselli, L., Angelici, F. M. \& Akani, G. C. Large elapids and arboreality: the ecology of Jameson's green mamba (Dendroaspis jamesoni) in an Afrotropical forested region. Contrib. Zool. 69, 147-155 (2000).

5. Akani, G. C., Angelici, F. M. \& Luiselli, L. Ecological data on the Goldie's tree cobra, Pseudohaje goldii (Elapidae) in southern Nigeria. Amphibia-Reptilia 26, 382-387 (2005).

6. Shine, R. et al. Ecology of cobras from southern Africa. J. Zool. 272, 183-193 (2007).

7. Jackson, K. Mean and Lowly Things: Snakes, Science, and Survival in the Congo. (Harvard University Press, 2008).

8. Alexander, G. J. Reproductive biology and maternal care of neonates in southern African python (Python natalensis). J. Zool. 305, 141-148 (2018)

9. Reading, C. J. et al. Are snake populations in widespread decline? Biol. Lett. 6, 777-780 (2010). 
10. Brown, L. C. Cashew and Cassava: Competing Cash Crops in the Farming System of the Makonde Plateau, Southern Tanzania. (Reading University Press, 1985).

11. Kabanza, A. et al. More people, more trees in South Eastern Tanzania: local and global drivers of land-use/cover changes. Afr. Geogr. Rev. 32, 44-58 (2013)

12. Kabanza, A. K. et al. Effectiveness of soil conservation measures in two contrasting landscape units of South Eastern Tanzania. Zeitschrift für Geomorphologie 57, 269-288 (2013).

13. Ngatunga, E. L., Dondeyne, S. \& Deckers, J. A. Is sulphur acidifying cashew soils of South Eastern Tanzania? Agric. Ecosyst. Environ. 95, 179-184 (2003).

14. Achten, W. M. et al. Gully erosion in South Eastern Tanzania: spatial distribution and topographic thresholds. Zeitschrift für Geomorphologie 52, 225-235 (2008).

15. Rossi, J. et al. Spatial structures of soil organic carbon in tropical forests-a case study of southeastern Tanzania. Catena 77, 19-27 (2009).

16. Luiselli, L., Angelici, F. M. \& Akani, G. C. Comparative feeding strategies and dietary plasticity of the sympatric cobras Naja melanoleuca and Naja nigricollis in three diverging Afrotropical habitats. Can. J. Zool. 80, 55-63 (2002).

17. Akani, G. C., Eyo, E., Odegbune, E., Eniang, E. A. \& Luiselli, L. Ecological patterns of anthropogenic mortality of suburban snakes in an African tropical region. Israel J. Zool. 48, 1-11 (2002).

18. Akani, G. C., Petrozzi, F., Eniang, E. A. \& Luiselli, L. Structure and composition of snake assemblages across three types of plantation in south-eastern Nigeria. Afr. J. Ecol. 53, 223-230 (2015).

19. Rowe, K. C. et al. Spatially heterogeneous impact of climate change on small mammals of montane California. Proc. R. Soc. B 282, 20141857 (2015).

20. Wykes, A. Snake Man. (Hamish Hamilton London, 1960).

21. Lane, M. Life with Ionides. (Hamish Hamilton London, 1963)

22. Ionides, C. J. P. A Hunter's Story. (W. H. Allen London, 1965).

23. Ionides, C. J. P. Mambas and Maneaters. (Mayflower London, 1968).

24. Ionides, C. J. P. Nature Notes (4): Notes on mamba (genus Dendroaspis) in the Southern Province of Tanganyika Territory. Afr. Wild Life 7, 303-314 (1953).

25. Spawls, S. C. J. P. Ionides: a commemoration. Herp. Rev. 49, 480-484 (2018).

26. Ionides, C. J. P. \& Pitman, C. R. S. Notes on three East African venomous snake populations. The Puku 3, 87-95 (1965).

27. Ionides, C. J. P. \& Pitman, C. R. S. Notes on two East African venomous snake populations. J. East Afr. Nat. Hist. Soc. Natl. Mus. 25, 116-121 (1965).

28. Wüster, W. et al. The phylogeny of cobras inferred from mitochondrial DNA sequences: evolution of venom spitting and the phylogeography of the African spitting cobras (Serpentes: Elapidae: Naja nigricollis complex). Mol. Phylogenet. Evol. 45, 437-453 (2007).

29. Wüster, W. et al. Integration of nuclear and mitochondrial gene sequences and morphology reveals unexpected diversity in the forest cobra (Naja melanoleuca) species complex in Central and West Africa (Serpentes: Elapidae). Zootaxa 4455, 68-98 (2018).

30. Nakagawa, S. A farewell to Bonferroni: the problems of low statistical power and publication bias. Behav. Ecol. 15, 1044-1045 (2004).

31. Penner, J., Fruteau, C., Range, F. \& Rodel, M. Finding a needle in a haystack: new methods of locating and working with rhinoceros vipers (Bitis rhinoceros). Herpetol. Rev. 39, 310 (2008).

32. Luiselli, L. Site occupancy and density of sympatric Gaboon viper (Bitis gabonica) and nose-horned viper (Bitis nasicornis). J. Trop. Ecol. 22, 555-564 (2006).

33. Bombi, P., Akani, G. C., Ebere, N. \& Luiselli, L. Potential effects of climate change on high-and low-abundance populations of the Gaboon viper (Bitis gabonica) and the nose-horned viper (B. nasicornis) in southern Nigeria. Herpetol. J. 21, 59-64 (2011).

34. Isemonger, R. M. Snakes of Africa. Southern, Central and East. (Thomas Nelson and Sons Johannesburg, 1962).

35. Shine, R. Reproductive strategies in snakes. Proc. R. Soc. B 270, 995-1004 (2003).

36. Luiselli, L. \& Akani, G. C. Diet of sympatric Gaboon Vipers (Bitis gabonica) and Nose-horned Vipers (Bitis nasicornis) in southern Nigeria. Afr. J. Herpetol. 52, 101-106 (2003).

37. Bittner, T. D., King, R. B. \& Kerfin, J. M. Effects of body size and melanism on the thermal biology of garter snakes (Thamnophis sirtalis). Copeia 2002, 477-482 (2002).

38. Shine, R., Sun, L. X., Kearney, M. \& Fitzgerald, M. Why do juvenile Chinese pit-vipers (Gloydius shedaoensis) select arboreal ambush sites? Ethology 108, 897-910 (2002).

39. Imansyah, M. J., Jessop, T. S., Ciofi, C. \& Akbar, Z. Ontogenetic differences in the spatial ecology of immature Komodo dragons. J. Zool. 274, 107-115 (2008)

40. Pizzatto, L., Almeida-Santos, S. M. \& Shine, R. Life-history adaptations to arboreality in snakes. Ecology 88, 359-366 (2007).

41. Seigel, R. A., Fitch, H. S. \& Ford, N. B. Variation in relative clutch mass in snakes among and within species. Herpetologica 42 , 179-185 (1986)

42. Henderson, R. W. Foraging and diet in west Indian Corallus enydris (Serpentes: Boidae). J. Herpetol. 27, 24-28 (1993).

43. Winstel, R. A., Sajdak, R. A. \& Henderson, R. W. Habitat utilization by the arboreal boa Corallus grenadensis in two ecologically disparate habitats on Grenada. Amphibia-Reptilia 19, 203-214 (1998).

\section{Acknowledgements}

Our greatest debt is to C.J.P. Ionides, for his meticulous record-keeping. We also thank Jonathan Leakey for providing access to the notebooks, Melanie Elphick for carefully transcribing the notes into a form suitable for analysis and for creating the Figures, and to A. Forbes-Watson, Johan Marais, and R. Auerbach for permission to use their photographs.

\section{Author contributions}

R.S. initiated the study and conducted the statistical analyses; S.S. obtained and scanned the notebooks; both authors contributed to writing the manuscript.

\section{Competing interests}

The authors declare no competing interests.

\section{Additional information}

Supplementary information is available for this paper at https://doi.org/10.1038/s41598-020-61974-4.

Correspondence and requests for materials should be addressed to R.S.

Reprints and permissions information is available at www.nature.com/reprints. 
Publisher's note Springer Nature remains neutral with regard to jurisdictional claims in published maps and institutional affiliations.

(c) (i) Open Access This article is licensed under a Creative Commons Attribution 4.0 International License, which permits use, sharing, adaptation, distribution and reproduction in any medium or format, as long as you give appropriate credit to the original author(s) and the source, provide a link to the Creative Commons license, and indicate if changes were made. The images or other third party material in this article are included in the article's Creative Commons license, unless indicated otherwise in a credit line to the material. If material is not included in the article's Creative Commons license and your intended use is not permitted by statutory regulation or exceeds the permitted use, you will need to obtain permission directly from the copyright holder. To view a copy of this license, visit http://creativecommons.org/licenses/by/4.0/.

(c) The Author(s) 2020 